\title{
Uso abusivo e cuidado não abusivo: Assistência a usuários de crack em cidade
}

\section{histórica}

\author{
Abusive use and non-abusive care: Assistance to crack users in historic city \\ Uso abusivo y cuidado no abusivo: Asistencia a usuarios de crack en una ciudad histórica
}

Recebido: 05/07/2021 | Revisado: 09/07/2021 | Aceito: 09/07/2021 | Publicado: 21/07/2021

Marcos Antônio Barbosa Pacheco

ORCID: https://orcid.org/0000-0002-3566-5462 Universidade Ceuma, Brasil

E-mail: mmmarco@terra.com.br

Marilaine Pereira Santiago

ORCID: https://orcid.org/0000-0003-1405-2234

Universidade Ceuma, Brasil

E-mail: mpsantiago29@gmail.com

Arlete Penha Cutrim

ORCID: https://orcid.org/0000-0001-8673-6390

Universidade Ceuma, Brasil

E-mail: arletecutrim@hotmail.com

Pryscilla Pérgola Oliveira

ORCID: https://orcid.org/0000-0002-8739-8992

Universidade Ceuma, Brasil

E-mail: cyllaoliver@hotmail.com

Jose Márcio Soares Leite

ORCID: https://orcid.org/0000-0002-4943-2213

Universidade Ceuma, Brasil

E-mail: jmsoaresleite@gmail.com

Claudia Barbastefano Monteiro

ORCID: https://orcid.org/0000-0002-3150-7424

Universidade Federal do Rio de Janeiro, Brasil E-mail: claudia.ipub@gmail.com

Cristina Maria Douat Loyola

ORCID: https://orcid.org/0000-0003-2824-6531

Universidade Ceuma, Brasil

E-mail: crisloyola@hotmail.com

\begin{abstract}
Resumo
Contexto: o abuso de drogas nos grandes centros urbanos que tem impactado diretamente na curva crescente de violência. Objetivo: analisar uma intervenção institucional no processo de assistência a um grupo de pessoas usuárias de drogas e vivendo em situação de rua, no centro histórico de São Luís - Maranhão, Brasil. Método: pesquisa ação, utilizando observação sistemática, como estratégia e método de investigação, foram analisados os aspectos institucionais e assistenciais das medidas, a forma da abordagem e do seguimento do cuidado à saúde das pessoas assistidas. Resultados: evidenciou-se a necessidade de reconceituações sobre o uso e o cuidado não abusivo. Conclusões: as diferentes formas de organizar o cuidado e assistência a usuários de drogas exigem uma postura assistencial que exorbita a competência técnica de uma única abordagem, incluindo-se uma visão mais holística e integradora.
\end{abstract}

Palavras-chave: Saúde pública; Drogas ilícitas; Integralidade em saúde.

\section{Abstract}

Background: drug abuse in large urban centers that has directly impacted the growing curve of violence. Objective: To analyze an institutional intervention in the care process for a group of drug users living in homeless situations in the historic center of São Luís do Maranhão, Brazil. Method: action research, using systematic observation, as a strategy and research method, institutional and assistance aspects of the measures, especially the approach and followup of health care of assisted people. Results: There was a need for reconceptualization about use and non-abusive care. Conclusions: The different ways of organizing care and assistance to drug users require a care stance that exaggerates the technical competence of a single approach including a more holistic and integrative view.

Keywords: Public health; Street drugs; Integrality in health. 


\begin{abstract}
Resumen
Contexto: abuso de drogas en los grandes centros urbanos que ha impactado directamente en la curva ascendente de la violencia. Objetivo: analizar una intervención institucional en el proceso de atención a un grupo de usuarios de drogas que viven en las calles del centro histórico de São Luís - Maranhão, Brasil. Método: investigación acción, utilizando la observación sistemática como estrategia y método de investigación, se analizaron los aspectos institucionales y asistenciales de las medidas, el abordaje y seguimiento de la atención de salud de las personas atendidas. Resultados: se evidenció la necesidad de reconceptualización de uso y cuidado no abusivo. Conclusiones: las diferentes formas de organizar la atención y la asistencia a los consumidores de drogas requieren una postura de cuidado que excede la competencia técnica de un solo enfoque, incluyendo una visión más holística e integradora.

Palabras clave: Salud pública; Abuso de drogas; Integralidad en salud.
\end{abstract}

\title{
1. Introdução
}

Com a crescente e progressiva prevalência de uso de drogas, sobretudo do crack, nas cidades brasileiras, com destaque para as discussões polêmicas que envolvem essa questão, notadamente no caso das assim denominadas “cracolândias", impõe-se ao poder público uma série de respostas objetivas para um problema concreto. O que fazer? Como fazer? Qual o protocolo? Por que fazer ou não fazer? Esse acervo de problematizações se torna mais complexo quando se ressalta a transversalidade do tema do uso e abuso de drogas.

O início do uso de crack no Brasil se dá no final da década de 1980, e com rápida expansão, principalmente na população mais vulnerabilidade social. Os usuários de crack geralmente são homens, jovens, pouco escolarizados, que vivem em situação de rua sem renda (Almeida, Santos, Brito, Silva, \& Nappo, 2018).

Em que pese às discussões e polêmicas envolvendo o III Levantamento Nacional sobre o Uso de Drogas pela População Brasileira (Carlin, 2006), que apontou a inexistência de uma "epidemia" de crack no país, mas ressaltando uma prevalência de $0,9 \%$ de pessoas, na população pesquisada, que já usou ao menos uma vez ou usa eventualmente, significa falar de dois milhões de pessoas. Trata-se, portanto, de um número muito grande de pessoas que de alguma forma estão diretamente expostas, eventual ou regularmente, usando crack, sem falar nas outras drogas (Bastos, Vasconcellos, De Boni, Reis, \& Coutinho, 2017).

O presente estudo desenvolveu uma análise do tema, tomando como referência empírica uma experiência desenvolvida por um Grupo de Trabalho (GT), articulado pelo Fórum Estadual de Políticas sobre Drogas, na cidade de São Luís no Maranhão. O GT foi formado para intervir e controlar uma zona de uso de crack que já se apresentava em formação, em um bairro conhecido como Praia Grande, no Centro Histórico do município.

No bairro existem vários pontos de encontros de usuários de drogas, popularmente denominados de "bocas de fumo", mas aqui estamos tratando do território como um todo. A maioria desses usuários está cadastrada pelo serviço de abordagem social da Secretaria Municipal da Criança e Ação Social (Semcas), que mantém um equipamento denominando "Casa do Bairro" dentro do território, onde são realizados atendimentos diversos nas áreas sociais e da saúde. E foi exatamente na Casa do Bairro, que iniciamos a experiência de atendimento médico, como parte das estratégias de aproximação.

A questão do uso de drogas pode ser vista sob várias perspectivas. É um problema de saúde, mas, também, uma questão relevante no âmbito da assistência social e um grave (e agudo) problema de segurança pública (Zeferino, Fermo, Fialho, Kenthi, \& Bastos, 2019). Portanto, não há um único ou exclusivo modo de abordá-lo. Essa sua natureza multimodal exige, igualmente, um olhar diferenciado, quer se trate de um processo de intervenção (ações em curso ou medidas tomadas pelo poder público ou entidades não governamentais); ou em um processo de investigação regular (uma pesquisa acadêmica).

É possível identificar distintas dimensões da questão. Buscou-se, através de uma análise crítica, traçar algumas diretrizes, alternativas e interfaces no processo de abordagem e seguimento do cuidado ofertado aos usuários de drogas. A pesquisa tem um recorte predominante sobre a assistência à saúde das pessoas atendidas pelo GT. Contudo, numa perspectiva 
bem ampla, considerou as dimensões e condições clínicas, mas, também, aspectos sociais, identitários e subjetivos das pessoas assistidas. Portanto, está se falando de uma clínica ampliada.

O conceito de clínica aqui utilizado se refere ao cuidado multiprofissional e à atenção transdisciplinar, prestado a qualquer pessoa ou usuário de serviços de saúde, assistido por qualquer profissional, em qualquer lugar. Não é uma referência ao estritamente médico, mas, sim, ao uso no sentido de uma relação intersubjetiva entre um cuidador (tecnicamente habilitado) e uma pessoa ou grupo social a ser abordado, acolhido e cuidado (Brasil, 2009). Clínica aqui também deve ser entendida como produto de uma mediação entre os vários campos de saberes que se interceptam na complexidade do problema do abuso de drogas.

A abordagem desse grave problema de saúde e segurança pública, nos leva a pensar que não podemos abordá-lo com uma clínica "qualquer". E as experiências têm mostrado que não é possível fazê-la com a clínica de consultório tradicional, enclausurada ou encerrada entre as paredes de uma instituição, quer seja hospitalar ou ambulatorial, mas remanescente da forma tradicional de fazer medicina, isto é, sob demanda espontânea da clientela. Pelo contrário, imagina-se que, para enfrentar o problema do abuso de drogas, deveremos ter uma clínica aberta e multimodal, capaz de se mesclar com as dimensões técnica e popular que o problema envolve. Uma clínica "na" e "para" a rua (Brasil, 2011).

\section{Metodologia}

A estratégia metodológica desta pesquisa foi de natureza qualitativa, na linha da pesquisa-ação-participante (Barbier, 1985), que tem por finalidade contribuir simultaneamente para o alivio das preocupações de ordem prática e para o desenvolvimento da ciência. Neste tipo de pesquisa, onde a gênese social precede a gênese teórica e metodológica, a implicação do pesquisador é uma das características do processo de investigação (Felcher, Ferreira, \& Folmer, 2017). Os dados empíricos foram colhidos depois de mais de 90 horas de observação sistemática, no período de abril a junho de 2018, numa zona de uso de crack em São Luís e nas reuniões preparatórias, para a intervenção institucional nesta área, e nas ações e serviços ofertados na assistência aos usuários de drogas em situação de rua. Colheram-se dados também em fontes primárias, como atas de reuniões, cadastros de pessoas atendidas e prontuários clínicos.

A análise do caso e método proposto foi de observação sistemática como técnica de pesquisa e a análise de situação como instrumento de mediação entre o problema e os autores utilizados na sua discussão.

O objetivo geral foi o de analisar as ações institucionais sobre usuários de drogas em situação de rua, e como objetivos específicos buscou-se compreender a forma de abordagem aos usuários de crack, discutir o acolhimento e o seguimento do cuidado.

A coleta de dados envolveu um planejamento minucioso, que incluiu a obtenção da programação dos profissionais na área de intervenção e um intenso trabalho de campo, acompanhando as ações junto à população, objeto da intervenção dos profissionais cujas anotações foram posteriormente analisadas e cotejadas com referências teóricas a partir de uma abordagem exegética (os sentidos do texto) e dialética (as contradições do contexto).

O projeto de pesquisa, que deu origem a esta investigação, foi aprovado pelo Comitê de Ética em Pesquisa (CEP) com parecer consubstanciado número 2.592.058, tendo em vista a resolução 466/12 do Conselho Nacional de Saúde (Conep) (Brasil, 2013).

\section{Resultados e Discussão}

Na descrição do uso abusivo, o local pesquisado foi a zona de uso de crack no centro de São Luís. Neste território, existem alguns pontos onde se concentram usuários de drogas e/ou moradores em situação de rua, incluindo aqueles que 
moram na rua porque não têm nenhum vínculo familiar, os que ficam na rua porque não gostam da família e os que gostam da rua, embora durmam com a família em casa.

Esta complexidade prática e conceitual foi estudada, apontando que a circunstância de estar na rua possui nuances (Varanda \& Adorno, 2004). Os termos "homeless" (sem lar, em tradução livre) e "roofless" (sem teto) não são categorias que se sobrepõem exatamente. Ser sem-teto, pode não significar, exatamente, ser sem lar, onde a ausência de um lar implica, também, a falta de laços familiares, de redes sociais, de ligação entre indivíduos e a sociedade, e as várias possibilidades, ainda que esgarçadas das ligações familiares. Como em nossos dados empíricos, esta realidade não é linear (Quintão, 2012).

São muitas as situações, todas cadastradas pelo serviço social da prefeitura, a maioria usuários regulares de álcool e outras drogas, sobretudo do crack. O perfil sociodemográfico das pessoas foi levantado a partir do cadastro da Semcas, contudo com uma atenção às limitações sobre este tipo de fonte, para não incorrer no estado de ingenuidade científica, pois não se trata de um experimento nem de um simples levantamento de dados. Mas, sim, da observação de um contexto complexo.

O GT analisou 276 pessoas cadastradas e relacionou as seguintes variáveis: a) sexo, sendo $67 \%$ masculino e $33 \%$ feminino; b) faixa etária, subdividida por sexo; c) substância mais utilizada, conforme Tabela1.

Tabela1 - Perfil sociodemográfico por faixa etária e sexo.

\begin{tabular}{|l|l|l|}
\hline Idade & Masculino - \% & Feminino - \% \\
\hline 17 a 30 anos & $29 \%$ & $39 \%$ \\
\hline 31 a 45 anos & $57 \%$ & $40 \%$ \\
\hline 46 a 60 anos & $12 \%$ & $19 \%$ \\
\hline 61 a 100 anos & $2 \%$ & $2 \%$ \\
\hline
\end{tabular}

Fonte: Autores.

A maioria das pessoas cadastradas era do sexo masculino, aproximadamente dois terços. Isso ocorre com a maioria de populações usuárias de drogas. Homens são em geral mais consumidores de drogas que mulheres. E também é maioria entre as pessoas que se encontram em situação de rua. Estes dados são confirmados amplamente pelo estudo de Carlini et al. (2006), realizado em 108 cidades brasileiras onde se verifica que, no Brasil como no Chile e nos EUA, o uso de álcool é maior para o sexo masculino quando comparado ao feminino, em cerca de 20\% maior, conforme Tabela 2.

Tabela 2 - Substância usada.

\begin{tabular}{|l|l|}
\hline Substância & Porcentagem de uso \\
\hline Maconha & $19 \%$ \\
\hline Álcool & $38 \%$ \\
\hline Crack & $42 \%$ \\
\hline Solvente & $1 \%$ \\
\hline
\end{tabular}

Fonte: Autores.

O álcool é a substância psicoativa mais consumida no mundo, quando se analisa zonas de multiuso e não locais específicos, como esse local da pesquisa. O álcool também é considerado a droga mais utilizada como porta de entrada para o consumo de outras drogas. Estes dados são encontrados também em estudo internacional, onde o álcool aparece como a substância mais comum para primeiro uso. No grupo pesquisado o uso do crack foi duas vezes mais frequente que o da maconha, apontando o avanço significativo desse tipo de droga entre nós (Barry et al., 2016). 
Lancetti (2015) enumera quatro possibilidades explicativas para se formar um toxicômano: o neurônio, o "demônio", o narcisismo e o insuportável da vida. De início a teoria de uma enfermidade cerebral, relacionada à produção e esgotamento de aminas cerebrais; ou a explicação religiosa de presença do demônio; ou uma explicação mais afeita à psicanálise, onde o toxicômano se constituiu a partir de um narcisismo mal elaborado, ou o uso de drogas tornando suportável certo insuportável de viver. As teorias explicativas, do neurônio e do demônio, são focadas na droga em si e na abstinência, com grande orientação de tratamento moral.

Encontraram-se, no GT, as duas grandes vertentes para trabalhar com as zonas de uso: aqueles com um viés mais higienista, defendendo a limpeza da rua e a remoção compulsória das pessoas, mais afeitos às explicações um e dois acima; e a outra vertente com um viés mais autonomista, isto é, defendendo o direito à autonomia plena do usuário, inclusive de usar e escolher o lugar de usar a droga, neste caso o espaço público da rua, mais condizentes com as teorias de número três e quatro, acima expostas. Contudo, um consenso tornou possível a existência do grupo: a necessidade de intervenção.

Para alguns componentes do GT, o caso era de polícia; para outros, o caso era de política. Para uma terceira concepção, nem exclusivamente de polícia militar ou de política social, mas, sim, um caso típico de abordagem interinstitucional, com mediação integrada a partir das diferentes lógicas, cuidando de forma não abusiva.

Contudo, este cuidado não se refere aqui à clínica médica tradicional, com as limitações que uma concepção positivista lhe impõe desde a segunda metade do século XIX, com seu viés biomédico e atualmente "high tech". Pelo contrário, está se falando de uma clínica ampliada, uma clínica que incorpora valores e concepções de outros campos de saberes, uma clínica "high touch", baseada em evidência, mas, também, na experiência sensível e na narrativa das pessoas a serem acolhidas e cuidadas. Trabalhamos aqui com a clínica da complexidade invertida (Lancetti, 2006) essas experimentações realizadas no território.

Os usuários que se encontrou na rua, muitos ativos e criativos, mas, também, cativos daquela situação de dependência química, precisavam de um resgate da sua dignidade, situações de tamanha complexidade nas quais uma clínica tradicional não teria competência para atuar. Era preciso pensar criativamente a propedêutica convencional. Aqueles usuários necessitavam de uma clínica que operasse a potência de problematizar, e integrar a relação entre o normal e o patológico.

Esses conceitos, mesmo naquele contexto e diante daquelas pessoas, estavam despossuídos de sua semântica tradicional. Afinal, diante de um usuário de drogas, o que é o normal, a norma e o anormal?

Canguilhem (2009, p. 13), ao tratar da discussão entre os conceitos de normal e patológico, faz uma crítica direta à grande influência do positivismo sobre a forma como esses conceitos foram sendo construídos, no âmbito da medicina, ao longo da primeira metade do século XX, em grande parte, fundados na ideia quantitativa de anormal como um hipo/hiper. Contudo, o autor vai buscar uma concepção mais qualitativa para explicar a relação entre o normal e o patológico. E faz uma interessante ressalva sobre como a psiquiatria de sua época já relativizava esses conceitos ou, pelo menos, a forma como foram sendo concebidos (Canguilhem, 2009).

Essa mediação entre o normal e o patológico já era, por assim dizer, um exercício, dificílimo, mas extremamente necessário nas circunstâncias encontradas pelo GT. Nesse sentido é que se faz uma ancoragem de análise a partir do pensamento de Foucault (1980), do exercício crítico-reflexivo que sua obra impõe sobre o conceito de clínica, de suas múltiplas dimensões sócio-históricas, isto é, como um conceito construído social e historicamente.

Na obra O nascimento da clínica, Foucault (1980) faz uma discussão conceitual sobre a medicina e a clínica, e de como se deu a passagem, no início do século XIX, da medicina clássica (medicina do pensar sobre a doença abstrata) à medicina moderna, também denominada de medicina clínica ou anátomo-clínica (medicina do olhar sobre um corpo concreto). São concepções históricas construídas socialmente sobre a medicina e sobre a clínica que refletem muito bem a forma como se 
dava a percepção da doença ou do patológico. Foucault (1980, p. 60) ressalta que a medicina encontra sua possibilidade de ser e permanecer, na clínica, portanto, a clínica passa a ser a razão da medicina.

A medicina tem agora, na modernidade, uma racionalidade - a racionalidade clínica, construída social e historicamente. Assim se expressa o autor: "Para compreender o sentido e a estrutura da experiência clínica é preciso, em primeiro lugar, refazer a história das instituições em que se manifestou seu esforço de organização" (1980, p. 63). A partir daí o autor vai discutir como a instituição hospital se tornou, progressivamente, de hospital da miséria e morte para um espaço de agregação de conhecimento clínico; enfim, a "clínica se toma, portanto, um momento essencial da coerência científica, mas também da utilidade social e da pureza política da nova organização médica” (Foucault, 1980).

Isso ajuda a compreender que a medicina e, por conseguinte a clínica é uma construção que sofre forte influência de seu tempo e lugar, das suas formulações, conceitos e concepções sobre o normal e o anormal, o sadio e o patológico. Como afirma o autor:

Para que a experiência clínica fosse possível como forma de conhecimento, foi preciso toda uma reorganização do campo hospitalar, uma nova definição do estatuto do doente na sociedade e a instauração de uma determinada relação entre a assistência e a experiência (FOUCAULT, 1980, p. 226).

Vale também introduzir nessa discussão a contribuição de Canguilhem (2009), para quem, diante de condições ou circunstâncias complexas, é sempre preciso considerar a ideia de um "corpo subjetivo", como expressão de uma clínica objetiva (como técnica de tratar) e subjetiva (como arte de cuidar).

Canguilhem (2009, p. 93) reforça a ideia da impossibilidade de uma "patologia objetiva" na medida em que, clinicamente, a doença em si não existe, mas, sim, o doente. Portanto, a clínica deverá, preponderantemente, ser sobre o sujeito (o indivíduo) e não sobre um objeto (a lesão). Neste sentido é que se ressalta a importância de uma medicina voltada para o sujeito, na sua singularidade, na sua identidade, na sua subjetividade. Em síntese, toda medicina e, por extensão, a clínica são subjetivas ou, no mínimo, intersubjetivas. Nas palavras do autor: "Portanto, existe medicina, em primeiro lugar, porque os homens se sentem doentes. É apenas em segundo lugar que os homens, pelo fato de existir uma medicina, sabem em que consiste sua doença" (Canguilhem, 2009).

A primeira lição aprendida com aqueles usuários é que não havia uma forma ou fórmula única para ser aplicada, pois cada caso era um caso, para cada cliente uma clínica diferente, uma clínica convergente. Seria uma clínica multiprofissional, construída com um cuidado singular, comprometida com a autonomia e os direitos do usuário, mas vinculada ao objetivo de integrar a dignidade individual ao meio social em que vive e convive, para além daquele espaço da rua, uma clínica de convergência social. Exigia-se de todos outro olhar, uma outra lógica, uma outra técnica, outra ética e uma outra estética.

Um grupo de profissionais dos mais diversos equipamentos do poder público municipal e estadual (CAPS ad, Unidade de Acolhimento, Abordagem Social, polícia local, entre outros) se dispôs a fazer um acolhimento nos lugares onde havia maior concentração de usuários de drogas. Uma tenda era armada na praça ou na rua, com algumas mesas e cadeiras, um lanche e uma equipe multiprofissional a serviço de quem quisesse se aproximar. Era uma aproximação, com postura acolhedora, sem nenhuma característica de compulsoriedade, com respeito à autonomia da pessoa. Estavam todos à paisana, sem uniformes, sem uniformidades ou uniformizações.

Decerto que o GT trabalhava com a perspectiva terapêutica, mas com outros significados, outras formas de fazer e desfazer. Certa era a necessidade de um novo olhar, um olhar que não fosse redutor, "mas fundador do indivíduo em sua qualidade irredutível. E, assim, torna-se possível organizar em torno dele uma linguagem racional e razoável" (Foucault, 1980). Essa perspectiva racional e razoável partia do princípio de que havia uma racionalidade (de abordagem) e uma razão (do sujeito abordado) que deveriam, necessariamente, se articular, no sentido de uma relação humanizada (entre assistente e assistido), destituída de qualquer forma de violência, física ou simbólica. 
O GT estava diante de uma experiência clínica diferente, que não estava a serviço da tradição médica, do pensamento comum, ou do "senso comum douto" que discorre sobre a percepção acrítica da realidade; de como, mesmo o profissional academicamente titulado, pode deixar-se levar por uma percepção isenta de qualquer problematização o que reduz significativamente sua capacidade de intervenção. Estava-se ali a serviço dos novos sujeitos, estes que surgiam daquela situação objetiva, mas não eram meros objetos de intervenções decididas e definidas a priori (Bourdieu, 2006).

Precisava-se instituir a clínica do sujeito e para o sujeito, em alguma medida, objetivo. Estava-se diante de um sofrimento doença, mas não havia um "mal no corpo", uma configuração patológica (Foucault, 1980). A clínica da transgressão deveria dar lugar à clínica do acolhimento, porque, além de não se estar lidando com uma doença configurável, também se estava numa arena em disputa contra (às vezes a favor) a internação involuntária, com o respaldo dos órgãos de segurança pública e dos próprios órgãos do sistema de justiça.

O objeto do discurso também pode ser um sujeito em curso, sem que as figuras da objetividade sejam por isso alteradas. Foi essa reorganização formal e em profundidade, mais do que o abandono das teorias e dos velhos sistemas que criou a possibilidade de uma experiência clínica (Foucault, 1980).

Por outro lado, ao tomar o problema da dependência química, a julgar objetivamente, somente pela sua prevalência, é possível incorrer numa situação problematizada por Foucault, quando trata da "política médica", da vigilância das séries históricas e dos registros sanitários. Assim se expressa: "seu suporte não é a percepção do doente em sua singularidade, mas, antes, é uma consciência coletiva de todas as informações que se cruzam, crescendo em uma ramagem complexa e sempre abundante" (Foucault, 1980). Aqui, trata-se de lidar com uma mediação entre a objetividade dos casos como um todo e a subjetividade de cada caso em particular. Eis o desafio da clínica convergente, que converge a partir da diversidade de vários olhares e percepções e se coloca a serviço do sujeito.

A primeira tarefa do médico e de qualquer profissional de saúde (e da clínica) é, portanto, política (Foucault, 1980). E isso não é pouca coisa, porque implica em discorrer e discutir sobre a função social da política pública de saúde, naquele cenário em que se atua clinicamente; buscar tornar real o que é formal (a legislação abstrata); inserir nos programas governamentais os dramas pessoais de sua clientela esfarrapada. Homens e mulheres em situação de rua, usuários de drogas e viajantes de outras lógicas que não aquela da doença classificável e localizável como um "mal do corpo".

Quando um médico fala da doença de Basedow, isto é, de bócio exoftálmico, ele designa um estado de disfunção endócrina cujo enunciado dos sintomas, o diagnóstico etiológico, o prognóstico e a decisão terapêutica são sustentados por uma sucessão de pesquisas clínicas e experimentos, de exames de laboratórios, no decorrer dos quais os doentes são tratados não como sujeitos, mas como objetos (Canguilhem, 2005).

As pessoas usuárias de crack da Praia Grande apresentavam problemas objetivos que se traduziam subjetivamente. E isso exige uma postura assistencial que, exorbita a competência de uma única abordagem técnica. Uma leitura de Canguilhem (2005) impõe uma ressignificação dos conceitos de normal e patológico, dos sentidos e da semântica que esses termos carregam. Também do lugar do sujeito e da sua sujeição na relação profissional-paciente. Os conceitos exorbitam as palavras. Portanto, repensar os conceitos e de como aplicá-los a pessoas em determinadas condições clínicas, pode fazer muita diferença, para pensar em um sistema ao mesmo tempo acolhedor e resolutivo, afetivo e efetivo, mais inteligente e tecnicamente muito mais diversificado.

Tratava-se de um sistema que contemplasse os diferentes sentimentos e comportamentos dos sujeitos em questão, que abrisse mão da medicalização excessiva, mas focado naquilo que já vem sendo proposto com o nome de plano terapêutico singular. Ainda que se respeite a denominada "medicina baseada em evidência", não se trata de fazer uma "medicina probabilística" (Canguilhem, 2005); não se trata de enlatar o paciente em um protocolo genérico, mas trabalhar com diretrizes que norteiem e orientem o plano terapêutico singular ou específico para cada sujeito. 
Estudo registra que 1,2\% das internações no SUS estão diretamente ligadas ao consumo de drogas, e, destas, 69\% foram causadas pelo uso do álcool (Reis \& Bastos, 2016). Portanto, quando se fala de populações mais vulneráveis e de relativa baixa resiliência para consumo de crack, é preciso pensar além de uma dimensão biológica. É necessário pensar numa dimensão sociológica; é preciso criar condições de inserção no mercado de trabalho e em espaços ocupacionais; condições de moradia dentro de uma lógica que não pareça confinamento domiciliar. E não adianta criminalizar, mas acolher e buscar reduzir o dano.

Algumas experiências, no Brasil, baseadas nas estratégias de redução de dano, têm demonstrado que é possível obter resultados satisfatórios em relação ao controle do abuso de drogas (Machado \& Boarini, 2013; Silveira, 2016).Em se tratando da condição humana, precisamos "pensar sobre o que estamos fazendo, e como estamos fazendo" (Arendt, 2001). Pensar sobre essa realidade que proporcionou ao GT lidar com pacientes socialmente muito vulneráveis, em situação de rua, usuários de crack, que se apresentaram à clínica com um quadro, por exemplo, de taquicardia; e elucidar suas possíveis origens, sem descartar de imediato uma causa endócrina (hipertireoidismo?), ou tóxica (abstinência?), ou psicossomática (ansiedade fóbica?), ou mesmo uma causa cardíaca primária.

Ou, por exemplo, uma gestante usuária de drogas, para a qual era preciso estratificar o risco da gravidez (habitual, médio ou alto risco?); associar e monitorar crescimento fetal, variação da pressão arterial e função renal, isso, preferencialmente, na rua ou na Casa do Bairro, porque estes sujeitos não se sujeitam ao ritual convencional dos espaços da medicina tradicional. Querem distância das unidades de saúde, onde, segundo suas narrativas, são mal compreendidos, incompreendidos ou simplesmente rejeitados. Renegados, como um hanseniano que fora rejeitado na referência para atendimentos de pacientes com hanseníase porque era usuário de drogas; e fora rejeitado na rede psicossocial porque era portador de hanseníase. Ou o sujeito com uma fratura cominutiva de cotovelo (com grande edema) humilhado no pronto atendimento por causa de seu estado de embriaguez. Constrangido, não esperou o atendimento; estava há sete dias sem nenhuma imobilização protetora, predispondo lesões irreversíveis na articulação.

$\mathrm{O}$ atendimento de outro senhor que se apresentou com queixa de dispneia; ao ser indagado se fumava, respondeu: "só maconha mesmo". A naturalidade desconcertou o médico assistente. O sintoma traçador da consulta traçava vários caminhos. Sua narrativa e história clínica sugeriam uma doença pulmonar obstrutiva crônica, predominantemente enfisematosa, mas possivelmente haveria algum componente infeccioso, tipo bronquite. Era, ainda, hipertenso e havia abandonado o tratamento com propranolol, porque não se dera bem. A indicação de betabloqueador (o propranolol) neste caso, causava broncoconstricção, e neste tipo de paciente, só piora o quadro.

A maior parte das pessoas atendidas apresentava múltiplas morbidades. Esta contingência mais que dobrava a demanda de cuidado, sobretudo pelas interações medicamentosas ou mesmo por alguma conduta iatrogênica, como aquela prescrita para o usuário de cannabis. Entre os usuários daquele território, uma prevalência de hipertensão e diabetes igual à população geral, mas com um complicador - baixíssima acessibilidade aos equipamentos de saúde, portanto, com um grau médio de complicações muito acima da população geral. Qual clínica é capaz de acolher, servir e tratar estes sujeitos?

São estes casos que nos fazem pensar e repensar sobre o modelo de clínica que se oferta nos serviços de saúde. A boa clínica, no cenário aqui discutido, se baseia nas boas práticas, e não, necessariamente, em um protocolo universal, dado que o esse problema é individual. Sem refutar a evidência clínica que, em última análise, deriva da boa prática, trata-se, antes de tudo, de convergir todas as experiências acumuladas pelos múltiplos campos de saberes na síntese para o cuidado com o sujeito.

O programa Consultório na Rua, regulamentado pela Portaria Ministerial GAB/MS n. ${ }^{\circ}$ 122/2011, tem se constituído numa experiência interessante, contudo sua uniformização (viatura plotada, cheia de logomarcas) às vezes afasta sujeitos que o 
imaginam como uma instituição ambulante, ou o associam ao sistema de segurança pública e não ao sistema de assistência à saúde ou da assistência social.

\section{Conclusão}

É preciso dar conta das questões levantadas que derivam do uso abusivo de drogas, que é fator de risco à vida, à vida digna. Isso significa ter uma política pública definida para controlar o problema, mas tendo em vista, necessariamente, que não se trata de um problema exclusivamente de segurança, ou da saúde, ou da assistência isoladamente, mas, sim, um problema que transversaliza todas essas políticas sociais.

Aos poucos houve consenso sobre o cuidado não abusivo, apoiado numa clínica ampliada, de convergência social, uma clínica sobre o sujeito (indivíduo) e não sobre o objeto (a droga). Optou-se pela estratégia da "tenda estendida". Isto é, montou-se uma equipe multidisciplinar e armou-se uma tenda próxima dos espaços onde estavam as pessoas que se queria assistir. Uma tenda com lanches e oportunidade de serem atendidos por uma clínica ampliada, por uma assistência social, por um agente público emitindo um documento, todos à paisana, sem instituições, sem perspectiva de cura, mas de cuidado!

Uma vez que as pessoas - usuários de drogas ou simplesmente moradores em situação de rua - se aproximavam para colher alguma dessas ofertas, iniciava-se um processo de sensibilização e convencimento para inseri-lo em algum protocolo assistencial da rede pública, ou da saúde. O protocolo a serviço das pessoas e não as pessoas enquadradas no protocolo.

O "combo assistencial", de lanche com avaliação médica, trouxe muita gente para a tenda. Sempre havia um médico atuando como clínico e um psiquiatra da equipe do Caps Ad, que junto com outros componentes da equipe formavam um time multidisciplinar. A van plotada do Programa Consultório na Rua não foi uma opção utilizada. A postura assistencial exorbita a competência de uma única abordagem técnica.

A experiência mostrou que se precisa insistir nessa forma de pensar e executar:

a) cada caso é um caso, portanto investir muito mais em projetos terapêuticos singulares - nada de tratamentos homogeneizados;

b) as intervenções individuais ou coletivas devem ser intersetoriais, não excessivamente institucionalizadas, sem protocolos fixos ou diretrizes excessivamente rígidas.

Nenhuma instituição isolada dá conta do problema pela extrema complexidade e carregado de muitos significados simbólicos e existenciais. A clínica existe para servir ao sujeito e não para sujeitá-lo, sabendo todos que a clínica, em geral, deve propor o cuidado e não a cura.

Outra dimensão essencial é o cenário sociocultural: considerar remanescências identitárias e a origem regional ou étnica das pessoas; instituir programas de enfrentamento da pobreza extrema no entorno desses espaços, oferecendo trabalho e moradia que não se assemelhem a punição e confinamento. Até porque uma boa clínica é também uma crítica social que produz, por outros meios, uma clínica social. Enfim, produzir uma técnica de cuidado focada e centrada na pessoa, objetiva e efetiva como técnica, mas subjetiva e afetiva como arte de cuidar.

\section{Referências}

Almeida, R. B. F. de, Santos, N. T. V., Brito, A. M. de, Silva, K. S. de B. e, \& Nappo, S. A. (2018). O tratamento da dependência na perspectiva das pessoas que fazem uso de crack. Interface - Comunicação, Saúde, Educação, 22(66), 745-756. https://doi.org/10.1590/1807-57622016.0940

Arendt, H. (2001). A condição humana. (F. Universitaria, Org.) (10a ed).

Barbier, R. (1985). Pesquisa ação na instituição educativa. (J. Zahar, Org.). 
Research, Society and Development, v. 10, n. 9, e8410917905, 2021

(CC BY 4.0) | ISSN 2525-3409 | DOI: http://dx.doi.org/10.33448/rsd-v10i9.17905

Barry, A. E., King, J., Sears, C., Harville, C., Bondoc, I., \& Joseph, K. (2016). Prioritizing Alcohol Prevention: Establishing Alcohol as the Gateway Drug and Linking Age of First Drink With Illicit Drug Use. Journal of School Health, 86(1), 31-38. https://doi.org/10.1111/josh.12351

Bastos, F. I. P. M., Vasconcellos, M. T. L. de, De Boni, R. B., Reis, N. B. dos, \& Coutinho, C. F. de S. (2017). III Levantamento Nacional sobre o uso de drogas pela população brasileira. (ICICT/FIOCRUZ, Org.). Rio de Janeiro.

Bourdieu, P. (2006). O poder simbólico. (B. B. (Memória e Sociedade)., Org.).

Brasil, M. da S. (2009). Clínica ampliada e compartilhada.

Brasil, M. da S. Portaria No 122, de 25 DE Janeiro de 2011 (2011).

Brasil, M. da S. - Resolução CNS Nº 466, de 12 de dezembro de 2012. (2013).

Canguilhem, G. (2005). Escritos sobre amedicia. (F. Universitária., Org.).

Canguilhem, G. (2009). O normal e o patológico. (: Forense Universitária, Org.) (6a ed).

Carlin, E. A. (2006). II Levantamento Domiciliar Sobre o Uso de Drogas Psicotrópicas no Brasil: Estudo Envolvendo as 108 Maiores Cidades do País. Dados, 106, 1-31. http://www.ncbi.nlm.nih.gov/pubmed/21108957

Felcher, C. D. O., Ferreira, A. L. A., \& Folmer, V. (2017). Da Pesquisa-Ação À Pesquisa Participante: Discussões a Partir De Uma Investigação Desenvolvida No Facebook. Experiência em Ensino de Ciências, 12(7), 1-18.

Foucault, M. (1980). O nascimento da clínica. (F. Universitária., Org.) (2a ed).

Lancetti, A. (2006). Clínica peripatética. (Hucitec., Org.).

Machado, L. V., \& Boarini, M. L. (2013). Políticas sobre drogas no Brasil: a estratégia de redução de danos. Psicologia: Ciência e Profissão, 33(3), 580-595. https://doi.org/10.1590/S1414-98932013000300006

Quintão, P. R. (2012). Morar na rua: há projeto possível? Arquitetura e Urbanismo USp. Faculdade de Arquitetura e Urbanismo da Universidade de São Paulo para.

Reis, N. B. dos, \& Bastos, F. I. P. M. (2016). Pesquisas sobre o Consumo de Drogas no Brasil. Eixo de Políticas e Fundamentos, 17.

Silveira, R. W. M. da. (2016). Redução de danos e acompanhamento terapêutico: aproximações possíveis. Revista Nufen: Phenom. Interd., 8(1), 110-128.

Varanda, W., \& Adorno, R. de C. F. (2004). Descartáveis urbanos: discutindo a complexidade da população de rua e o desafio para políticas de saúde. Saúde e Sociedade, 13(1), 56-69. https://doi.org/10.1590/S0104-12902004000100007

Zeferino, M. T., Fermo, V. C., Fialho, M. B., Kenthi, A., \& Bastos, F. I. (2019). Crack Cocaine Use Scene In The Capital Of The State Of Santa Catarina/Brazil: The (In)Visibility Of Users. Texto \& Contexto - Enfermagem, 28. https://doi.org/10.1590/1980-265x-tce-2017-0460 